\title{
Article \\ New Insights in Microbial Species Predicting Lung Function Decline in CF: Lessons from the MucoFong Project
}

\author{
Florence Francis ${ }^{1,2,+}$, Raphael Enaud ${ }^{3,4,5,+}$, Perrine Soret ${ }^{2,6,7}$, Florian Lussac-Sorton ${ }^{3,4,8}$, \\ Marta Avalos-Fernandez 2,6, MucoFong Investigation Group 9 , Stéphanie Bui 3,4,5 (D), Michael Fayon ${ }^{3,4,5}$, \\ Rodolphe Thiébaut ${ }^{1,2,6}$ and Laurence Delhaes ${ }^{3,4,8, *,+} \mathbb{D}$
}

1 CHU de Bordeaux, Department of Public Health, F-33000 Bordeaux, France; florence.francis@u-bordeaux.fr (F.F.); rodolphe.thiebaut@u-bordeaux.fr (R.T.)

2 Bordeaux Population Health Research Center, Univ. Bordeaux, Inserm, UMR 1219, F-33000 Bordeaux, France; perrine.soret@gmail.com (P.S.); marta.avalos-fernandez@u-bordeaux.fr (M.A.-F.)

3 Centre de Recherche Cardio-Thoracique de Bordeaux, Univ. Bordeaux, U1045, F-33000 Bordeaux, France; raphael.enaud@chu-bordeaux.fr (R.E.); florian.lussac-sorton@u-bordeaux.fr (F.L.-S.); stephanie.bui@chu-bordeaux.fr (S.B.); michael.fayon@chu-bordeaux.fr (M.F.)

4 CHU de Bordeaux, Univ. Bordeaux, FHU ACRONIM, F-33000 Bordeaux, France

5 CHU de Bordeaux, CRCM Pédiatrique, CIC 1401, F-33000 Bordeaux, France

6 INRIA SISTM Team, F-33405 Talence, France

7 Laboratoire Servier, 50 Rue Carnot, 92284 Suresnes, France

check for updates

Citation: Francis, F.; Enaud, R.;

Soret, P.; Lussac-Sorton, F.; AvalosFernandez, M.; MucoFong Investigation Group; Bui, S.; Fayon, M.; Thiébaut, R.; Delhaes, L. New Insights in Microbial Species Predicting Lung Function Decline in CF: Lessons from the MucoFong Project. J. Clin. Med. 2021, 10, 3725. https://doi.org/10.3390/ jcm10163725

Academic Editor: Sukhwinder Singh Sohal

Received: 21 June 2021

Accepted: 18 August 2021

Published: 21 August 2021

Publisher's Note: MDPI stays neutral with regard to jurisdictional claims in published maps and institutional affiliations.

Copyright: (c) 2021 by the authors. Licensee MDPI, Basel, Switzerland. This article is an open access article distributed under the terms and conditions of the Creative Commons Attribution (CC BY) license (https:// creativecommons.org/licenses/by/ $4.0 /)$.
CHU de Bordeaux, Service de Parasitologie-Mycologie, F-33000 Bordeaux, France

9 The Mucofong Investigation Group, 28 rue Roger Amsler, CEDEX 01, 49045 Angers, France; jean-philippe.bouchara@univ-angers.fr

* Correspondence: laurence.delhaes@u-bordeaux.fr; Tel.: +33-05-47-30-27-50

$+\quad$ These authors contributed equally.

\begin{abstract}
Several predictive models have been proposed to understand the microbial risk factors associated with cystic fibrosis (CF) progression. Very few have integrated fungal airways colonisation, which is increasingly recognized as a key player regarding CF progression. To assess the association between the percent predicted forced expiratory volume in $1 \mathrm{~s}$ (ppFEV1) change and the fungi or bacteria identified in the sputum, 299 CF patients from the "MucoFong" project were included and followed-up with over two years. The relationship between the microorganisms identified in the sputum and ppFEV1 course of patients was longitudinally analysed. An adjusted linear mixed model analysis was performed to evaluate the effect of a transient or chronic bacterial and/or fungal colonisation at inclusion on the ppFEV1 change over a two-year period. Pseudomonas aeruginosa, Achromobacter xylosoxidans, Stenotrophomonas maltophilia, and Candida albicans were associated with a significant ppFEV1 decrease. No significant association was found with other fungal colonisations. In addition, the ppFEV1 outcome in our model was $11.26 \%$ lower in patients presenting with a transient colonisation with non-pneumoniae Streptococcus species compared to other patients. These results confirm recently published data and provide new insights into bacterial and fungal colonisation as key factors for the assessment of lung function decline in CF patients.
\end{abstract}

Keywords: cystic fibrosis; longitudinal analysis; Aspergillus fumigatus; Candida albicans; mycobiota

\section{Introduction}

Cystic fibrosis (CF) is the most common inherited disease in Caucasian populations, affecting about 70,000 individuals in the world [1]. This multisystem disease affects primarily the lungs, causing repeated lung infections and chronic lung inflammation which lead to progressive respiratory failures associated with significant morbidity and early death.

Several predictive models have been proposed to identify risk factors associated with severe lung function decline, morbidity, or mortality in CF [2-15]. These models underscored the importance of several clinical factors, including microbial airway colonisations, 
when assessing morbidity and mortality in CF. However, none but two of these studies $[4,12]$ have taken into consideration fungal flora (mycobiota) of the CF airways. These two studies were focused on managing spontaneous pneumothorax and scoring the risk of death or lung transplantation (LT) in CF, respectively [4,12], and provided data and scores that might be useful for daily practice but need to be used by other clinicians from other CF centres. In addition, fungi are increasingly recognized as key players in the natural course of CF lung disease and as real threats in the case of lung transplantation (LT) [1,4,12,16-18].

In the present study, our aim was to determine whether bacterial and/or fungal colonisations of the airways were independently associated with CF patients' lung function progression in the French national multicentre longitudinal "MucoFong" study.

\section{Materials and Methods}

\subsection{Study Design and Population}

Data collected from the prospective MucoFong project, which was supported by the French National Clinical Research program ("PHRC" protocol number 06/1902, 2007-2012 [18,19]), were used in the present study. The main overall aim of MucoFong was to set-up a standardized mycological analysis of sputa and to estimate fungal prevalence rates in $\mathrm{CF}$, which led to an in-depth analysis of sputa.

\subsection{Ethics}

This study was approved by the Institutional Ethics Committees of Lille University Hospital (CPP Number: 06/84); written informed consent was provided by all participants $[18,19]$.

Clinical data including standard spirometry, therapeutic, radiological, and biological data along with allergic bronchopulmonary aspergillosis (ABPA) criteria were prospectively collected at each visit. CF participants underwent 3 visits during the 2 years of the followup [19].

\subsection{Microbial Analysis}

Bacterial cultures were performed in agreement with the European CF Society guidelines. Briefly, in agreement with the French guidelines, $10 \mu \mathrm{L}$ of pure sputum sample were plated on a selective agar for Gram-negative bacilli isolation (such as MacConkey type), a selective agar for Pseudomonas aeruginosa isolation (optional if the previous selective agar allows accurate identification of P. aeruginosa colonies), a selective agar for Burkholderia cepacia complex isolation (such as PC or BCSA), and a selective agar for Staphylococcus aureus isolation including small colony variants (e.g., hypersaline mannitol agar, chromogenic media). These media were incubated at $35 \pm 2{ }^{\circ} \mathrm{C}$ in an aerobic atmosphere for selective media and in a $\mathrm{CO}_{2}$-enriched atmosphere for non-selective media. A minimum detection limit equal to $10^{2} \mathrm{CFU} / \mathrm{mL}$ were used to interpret growth on each type of media. In parallel, $10 \mu \mathrm{L}$ of sample diluted to $1 / 1000$ (detection threshold equal to $10^{5} \mathrm{CFU} / \mathrm{mL}$ ) were plated on an agar allowing the growth of Streptococcus pneumoniae and S. aureus with inhibition of Gram-negative bacteria (e.g., fresh blood ANC, CAP), and a cooked blood agar with or without bacitracin and with growth factors for the cultivation of Haemophilus influenzae. These two media were incubated at $35 \pm 2{ }^{\circ} \mathrm{C}$ in a $\mathrm{CO}_{2}$-enriched atmosphere. Fungal growth was detected using 6 semi-selective media according to the same standardized protocol performed by all the participating centres as previously described [19].

Given their clinical relevance [8,16,20-22], the presence of the mucoid phenotype of $P$. aeruginosa isolates, and isolates of $S$. aureus with methicillin resistance (MRSA) or not (MSSA), B. cepacia complex, Achromobacter xylosoxidans, Stenotrophomonas maltophilia, nontuberculous mycobacteria, or Streptococcus species was recorded. If bacteria were recorded at least once during the year prior to the visit without meeting the criteria for chronic colonisation, bacterial colonisation was considered transient. Chronic colonisation with P. aeruginosa (and by extension with either S. aureus, S. maltophilia, B. cepacia complex, and 
A. xylosoxidans) was defined as the presence of bacterial isolates in 3 consecutive cultures with at least 1 month between the positive cultures, during the previous 6 months [20].

Chronic colonisation with Aspergillus fumigatus (and by extension with other fungal species) was deemed present when fungi were isolated in 2 consecutive cultures with at least 1 month between the positive cultures during the previous 12 months [23]. Transient fungal colonisation was defined as the presence of a given micromycete in one sample only, either at the inclusion visit or during the year prior to inclusion.

\subsection{Outcome Assessment}

Given its major role in clinical practice and as it is currently the gold standard measure of disease severity, percent predicted forced expiratory volume in $1 \mathrm{~s}$ (ppFEV1) was selected as the main outcome variable. Spirometry was carried out in each centre, for routine care, by approved services applying the recommendations of the American Thoracic Society and European Respiratory Society in force [24]. The median of this parameter (ppFEV1) was modelled to assess the relationship between microbial colonisations at inclusion and lung disease progression over the 2 years following inclusion.

\subsection{Prognostic Score Assessment}

The recently proposed risk score for the prediction of within 3-year death or lung transplantation (LT) [12] was estimated for each patient at inclusion. Based on the 8 predictors proposed (i.e., ppFEV1, body mass index (BMI), B. cepacia complex colonisation, number of intravenous antibiotics courses per year, number of days of hospitalization per year, oral corticosteroids therapy, long-term oxygen therapy, and non-invasive ventilation), a weighted continuous score was individually calculated, namely, a high prognostic score corresponding to a high risk of LT or death.

\subsection{Statistical Analysis}

Analyses were performed using the statistical analysis software SAS version 9.4 (SAS Institute, Cary, NC, USA). Descriptive analyses have been performed to summarize the CF population at inclusion and during the follow-up. Continuous variables were presented as mean with standard deviation (Mean $\pm \mathrm{SD}$ ) for normal distribution or median with interquartile range (25th-75th percentile, IQR) for non-normal distribution. Qualitative variables were presented as $n(\%)$.

As data have been collected repeatedly during the follow-up, a linear mixed model analysis was used to evaluate the effect of transient or chronic colonisations with fungi and/or bacteria at the inclusion on the changes of ppFEV1. The model included a random intercept; parameters were estimated with the maximum likelihood method. A graphical analysis of the data revealed a heterogeneous change of ppFEV1 values among patients throughout the follow-up. It was therefore decided to consider time as a discrete variable (one variable per visit). No additional time interaction was required in the model; therefore, the effects of bacteria or fungi were modelled as an average difference of ppFEV1 from the inclusion onward.

The analyses were adjusted for potential confounding factors (study centre, age, sex, BMI, ABPA, and gastroesophageal reflux). According to the unadjusted univariate analyses, potential microbial predictors of the outcome such as transient or chronic bacterial and fungal colonisations (yes/no) were initially introduced in the model. A univariate analysis compared ppFEV1 from patients infected/colonised with a given organism to all other patients. Parameters with $p \leq 0.25$ in unadjusted analyses were considered for inclusion in the multivariable model. Then, a stepwise procedure was performed in multivariable adjusted analyses to select the subset of variables independently associated with the outcome (significant threshold at 0.05).

Accordingly, an initial model including all selected variables at an unadjusted step was performed. Then, at each step, before a variable was selected to be removed from the model, a hypothesis test was performed in order to state whether its contribution was 
significant or not. The procedure ended when all non-significant variables were removed. Estimate fixed effects for significant parameters were reported as $\beta$ coefficient, confidence interval 95\% (95\% CI), and $p$-value. The $\beta$ coefficient represents the mean difference of the ppFEV1 change between, respectively, patients with a chronic or transient colonisation at inclusion and those without colonisation adjusted on other variables. A T-test or partial Fischer test was used to assess whether the $\beta$ coefficient was significantly different from zero. Residual plots (marginal and conditional) were analysed to check their normality and homoskedasticity.

Given the polymicrobial constitution of CF airways flora, additional analyses were implemented to search for potential interactions between microorganisms.

\subsection{Model Robustness}

To assess whether the microorganisms identified as associated with a poor ppFEV1 level in the main analysis were also associated with worse prognostic scores, an adjusted linear regression was performed using the prognostic score recently developed [12] as the outcome variable.

\section{Results}

\subsection{Patients' Characteristics}

A total of 299 patients were included in the study, of whom 237 were monitored at each visit during the 2 years of follow-up (Figure 1).

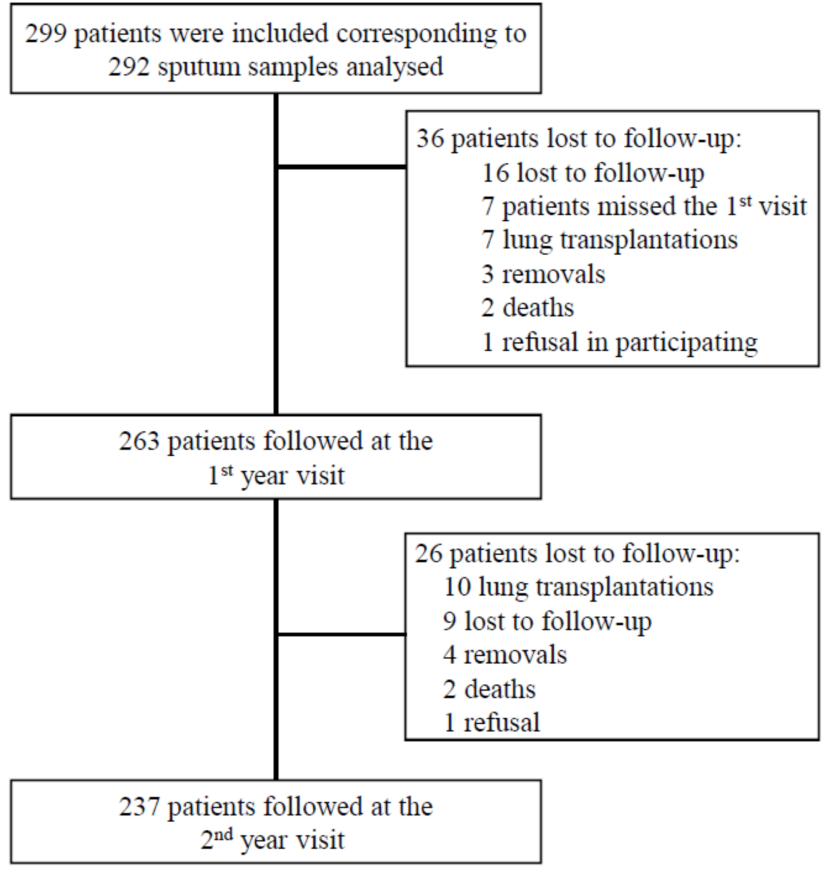

Figure 1. Flowchart showing inclusion and follow-up process of CF patients during MucoFong project.

Patients' characteristics, lung function results, microbial cultures of sputum, and therapeutics at study entrance are summarized in Table 1. Patients were adults, $23.7( \pm 10.9)$ years old; $143(47.8 \%)$ were female; $255(85.3 \%)$ had at least one F508del mutation of the CFTR gene; and the majority had exocrine pancreatic dysfunction $(78.6 \%)$. The median [IQR] Shwachman-Kulczycki score (S-K score, [2]) was 74.6 [IQR: 65-90]. 
Table 1. Characteristics of patients at inclusion $(n=299)$.

\begin{tabular}{|c|c|c|c|}
\hline Characteristics & $\underset{\text { Mata }}{\text { Missing }}$ & $\begin{array}{c}n \\
\text { or Median } \\
\text { or Mean }\end{array}$ & $\begin{array}{c}\% \\
\text { or [IQR] } \\
\text { or (SD) }\end{array}$ \\
\hline Age (years) & 0 & 23.7 & $(10.9)$ \\
\hline Gender (female) & 0 & 143 & 47.8 \\
\hline CFTR mutations & 0 & & \\
\hline F508del/F508del & & 119 & 39.8 \\
\hline F508del/other & & 136 & 45.5 \\
\hline Other/other or unknown & & 44 & 14.7 \\
\hline Comorbidities & 0 & & \\
\hline Exocrine pancreatic insufficiency & & 235 & 78.6 \\
\hline Diabetes mellitus & & 83 & 27.8 \\
\hline Gastroesophageal reflux & & 73 & 24.4 \\
\hline ABPA & & 69 & 23.1 \\
\hline Chronic sinusitis & & 58 & 19.4 \\
\hline Haemoptysis & & 55 & 18.4 \\
\hline Concomitant asthma & & 34 & 11.4 \\
\hline Pneumothorax & & 9 & 3.0 \\
\hline Pulmonary hypertension & & 5 & 1.7 \\
\hline BMI $\left(\mathrm{kg} / \mathrm{m}^{2}\right)$ & 1 & 19.9 & [17.6-21.3] \\
\hline Shwachman-Kulczycki score & 28 & 74.6 & {$[65-90]$} \\
\hline $\begin{array}{l}\text { Number of days of hospitalization during the last } \\
12 \text { months * }\end{array}$ & 10 & 7 & [1-115] \\
\hline Sputum bacterial cultures positive with & & & \\
\hline Staphylococcus aureus (methicillin susceptible) & & 80 & 27.4 \\
\hline Pseudomonas aeruginosa (non-mucoid strains) & & 75 & 26.4 \\
\hline Pseudomonas aeruginosa (mucoid strains) & & 77 & 22.6 \\
\hline Haemophilus influenzae & & 28 & 9.6 \\
\hline Staphylococcus aureus (methicillin resistant) & & 22 & 7.5 \\
\hline Non-pneumoniae Streptococcus species & & 19 & 6.5 \\
\hline Stenotrophomonas maltophilia & & 16 & 5.5 \\
\hline Alkaligenes xylosoxidans & & 12 & 4.1 \\
\hline Streptococcus pneumoniae & & 5 & 1.7 \\
\hline Bulkhoderia cepatia complex & & 3 & 1.0 \\
\hline Mycobacterium avium complex & & 4 & 1.4 \\
\hline Mycobacterium abscessus complex & & 5 & 1.7 \\
\hline Sputum fungal cultures positive with & 10 & & \\
\hline Candida albicans & & 136 & 45.5 \\
\hline Aspergillus fumigatus & & 80 & 26.8 \\
\hline Other moulds (Cladosporium sp., Penicillium sp.) & & 20 & 6.7 \\
\hline Scedosporium species & & 10 & 4.0 \\
\hline Aspergillus flavus & & 9 & 3.0 \\
\hline Candida parapsilosis & & 5 & 1.7 \\
\hline Other Aspergillus species & & 4 & 1.3 \\
\hline Candida glabrata & & 3 & 1.0 \\
\hline Other Candida species & & 3 & 1.0 \\
\hline Exophiala dermatitidis & & 2 & 0.7 \\
\hline Lomentospora prolificans & & 1 & 0.3 \\
\hline Medications & 0 & & \\
\hline Non-invasive ventilation & & 21 & 7.2 \\
\hline Long-term oxygen & & 32 & 10.7 \\
\hline Nebulized rhDNase & & 178 & 59.5 \\
\hline Inhaled antibiotics & & 86 & 28.8 \\
\hline Inhaled steroids & & 168 & 56.2 \\
\hline Azithromycin & & 162 & 54.2 \\
\hline Oral antibiotic courses during the last 12 months & & & \\
\hline 0 & & 75 & 25.1 \\
\hline 1 to 3 & & 161 & 53.8 \\
\hline$>3$ & & 63 & 21.1 \\
\hline Intravenous antibiotics during the last 12 months & & 153 & 51.2 \\
\hline Mean number of antibiotic courses & & 1 & [0-2] \\
\hline Systemic corticosteroids during the last 12 months & & 70 & 23.4 \\
\hline Other immunosuppressive treatment & & 3 & 1.0 \\
\hline Antifungal treatment during the last 6 months & & 61 & 20.4 \\
\hline
\end{tabular}

$\overline{\mathrm{ABPA}}$, allergic bronchopulmonary aspergillosis; BMI, body mass index. Antifungal treatment was: itraconazole in 48 , voriconazole in 14, fluconazole in 4 , and posaconazole in 5 of the cases. ${ }^{*}$ Excluding patients without hospitalization.

Most patients were colonised with P. aeruginosa, S. aureus, Haemophilus influenzae, and non-pneumoniae Streptococcus species (including S. mitis group species; $n=19,6.5 \%$; Table 1), and to a lesser degree with S. maltophilia, A. xylosoxidans, B. cepacia complex species 
and/or non-tuberculous mycobacteria (Table 1). Candida albicans (45.5\%) and A. fumigatus $(26.8 \%)$ were the two major fungal species at inclusion, whereas Aspergillus flavus and Scedosporium species were isolated, respectively, in 3\% and $4 \%$ of patients (Table 1 ). As previously described $[1,19]$, the number of fungal species isolated increased with patient age: from none $(18.9 \%)$ to one $(42 \%)$, two $(29.6 \%)$, three $(8.2 \%)$, four $(0.8 \%)$, and five $(0.4 \%)$ species. In addition, patients colonised with $P$. aeruginosa were mainly colonised with two or more microbial species. Indeed, 33 of the 75 patients colonised with nonmucoid $P$. aeruginosa were co-infected with only one of the following species: mucoid P. aeruginosa $(n=7)$, non-pneumoniae Streptococcus $(n=4), \operatorname{MSSA}(n=11), \operatorname{MRSA}(n=2)$, C. albicans $(n=4)$, or $A$. fumigatus $(n=5)$ species. Furthermore, 29 of the 77 patients colonized with $P$. aeruginosa (mucoid strains) were co-infected with only one of the following species: non-mucoid P. aeruginosa $(n=7)$, non-pneumoniae Streptococcus $(n=2), \operatorname{MSSA}(n=3), \operatorname{MRSA}$ $(n=1)$, C. albicans $(n=7)$, or A. fumigatus $(n=9)$ species. Transient and chronic colonisations with $P$. aeruginosa, $S$. aureus, C. albicans, or A. fumigatus were mainly observed at baseline (Figure $2 \mathrm{a}, \mathrm{b}$ ). Less than $5 \%$ were chronically colonised with S. maltophilia, A. xylosoxidans, A. flavus, or with the Scedosporium species (Figure $2 \mathrm{~b}$ ). Transient colonisation with nonpneumoniae Streptococcus and with C. albicans were observed in $9.2 \%$ and $26.4 \%$ of cases (Figure 2a), with a chronic colonisation with C. albicans being stated in $31.8 \%$ (Figure $2 \mathrm{~b}$ ).
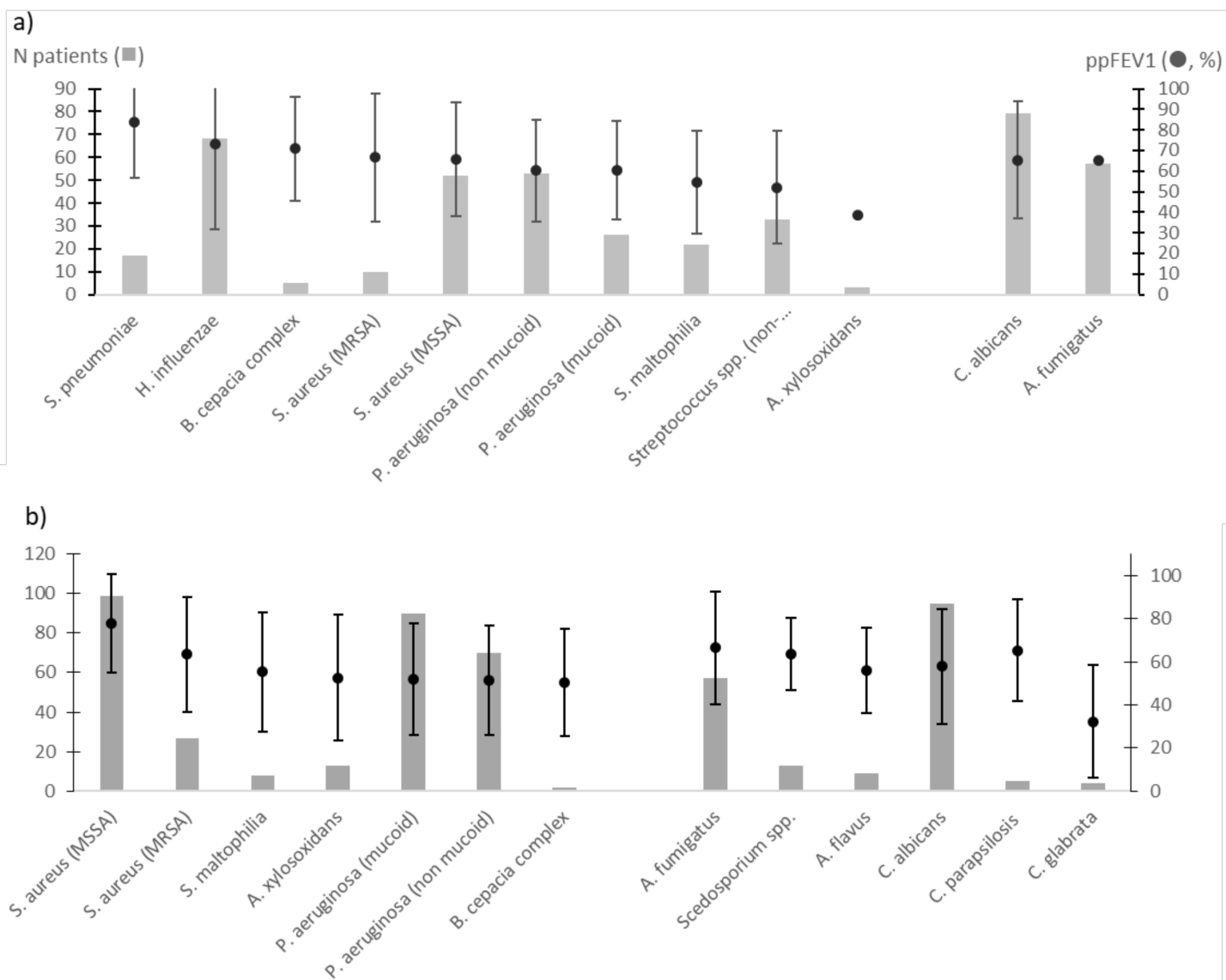

Figure 2. Mean ppFEV1 and its 95\% confidence interval of patients with microbial transient (a) and chronic (b) colonisations at inclusion.

Regarding medications at inclusion, most of the patients received rhDNAse $(170 / 299$; $59.5 \%)$, inhaled antibiotics $(86 / 299 ; 28.8 \%)$, and/or inhaled steroids $(168 / 299 ; 56.2 \%)$. While oral antibiotics, in particular ciprofloxacin formulations, remained the most often prescribed antimicrobial agents (74.9\%), intravenous antibiotics were prescribed in 153 cases (51.2\%) (Table 1). With respect to ABPA management, antifungal drugs were prescribed during the previous 6 months in 61 patients $(20.4 \%)$ (Table 1$)$. 


\section{2. ppFEV1 Characteristics and Univariate Analysis}

Medians of ppFEV1 were $67 \%$ [43-91\%] ( $n=295$ patients), 70\% [41-92\%] ( $n=254$ patients), and $69 \%[47-91 \%]$ ( $n=231$ patients) at inclusion, respectively, the first and second years of follow-up (Table 2).

Table 2. ppFEV1 predicted values and health care utilization during the 2 years of follow-up.

\begin{tabular}{cccc}
\hline $\begin{array}{c}\text { Variables Expressed as } \\
\text { Median [IQR] or Mean } \\
( \pm \text { SD)—(MV) }\end{array}$ & Inclusion & $\begin{array}{c}\text { 1st Follow-Up } \\
\text { (Year 1) }\end{array}$ & $\begin{array}{c}\text { 2nd Follow-Up } \\
\text { (Year 2) }\end{array}$ \\
\hline ppFEV1 & $67[43-91]-(4)$ & $70[41-92]-(36)$ & $69[47-91]-(68)$ \\
Outpatient visits (n) & $4[3-6]-(1)$ & $4[3-5]-(5)$ & $4[1-5]-(13)$ \\
Hospital admissions (n) & $0[0-1]-(1)$ & $0[0-2]-(6)$ & $0[0-1]-(13)$ \\
Days of hospitalization (n) & $12.2( \pm 16.6)-(10)$ & $13.0( \pm 18.3)-(59)$ & $12.7( \pm 16.8)-(22)$ \\
\hline
\end{tabular}

Data are presented as median with interquartile range [IQR] or mean and standard deviation $( \pm$ SD) followed by missing values (MV); ppFEV1, percent predicted forced expiratory volume in $1 \mathrm{~s}$; numbers of consultations (hospital admissions) and hospitalizations recorded during the last 12 months before the visit.

At baseline, ppFEV1 were lower in the case of a transient colonisation with nonpneumoniae Streptococcus species (Figure 2a), or chronic colonisation with P. aeruginosa, S. maltophilia, B. cepacia complex, A. xylosoxidans, C. albicans, A. flavus, and Candida glabrata (Figure $2 \mathrm{~b}$ ). An unadjusted analysis identified six microbial variables associated with a steeper decline of the ppFEV1 level compared to patients with no reported colonisation (Table 3). Among them, chronic infection with P. aeruginosa but also transient colonisation with P. aeruginosa (mucoid and non-mucoid strains) or colonisation with C. albicans were the most significantly associated with a decrease in the ppFEV1 level. Given the polymicrobial composition of the bacterial and fungal airway communities, numerous coinfections (non-mucoid or mucoid strains of $P$. aeruginosa in combination with either S. aureus, non-pneumoniae Streptococcus species, A. fumigatus, Scedosporium sp., C. albicans, or $C$. glabrata) were explored using a univariate analysis and did not reveal any significant impact on ppFEV1 (data not shown).

Table 3. Microbial factors at the inclusion associated with the average change of ppFEV1 during the 2 years of follow-up based on a univariate analysis.

\begin{tabular}{|c|c|c|c|c|}
\hline Microorganisms & $\begin{array}{l}\text { Type of Colonisation } \\
\text { (Number of Patients) }\end{array}$ & $\begin{array}{c}\beta \\
\text { Coefficient }\end{array}$ & $95 \% \mathrm{CI}$ & $p$-Value \\
\hline H. influenzae & Transient (68) & 5.23 & {$[1.47 ; 11.94]$} & 0.13 \\
\hline S. pneumoniae & Transient (17) & 14.79 & [3.47; 26.11] & 0.01 \\
\hline non-pneumoniae Streptococcus & Transient (33) & -6.93 & {$[-18.95 ; 5.09]$} & 0.25 \\
\hline S. aureus (methicillin susceptible) & Transient (53) & 4.60 & {$[-2.84 ; 12.04]$} & 0.17 \\
\hline & $\begin{array}{l}\text { Chronic (99) } \\
\text { Transient (10) }\end{array}$ & $\begin{array}{l}5.69 \\
1.60\end{array}$ & {$[-0.71 ; 12.10]$} & \\
\hline s. aureus (methicillin resistant) & $\begin{array}{l}\text { Iransient (10) } \\
\text { Chronic (27) }\end{array}$ & -6.44 & $\begin{array}{c}{[-13.09 ; 16.28]} \\
{[-15.72 ; 2.84}\end{array}$ & 0.38 \\
\hline P. aeruginosa (non-mucoid strains) & $\begin{array}{l}\text { Transient (53) } \\
\text { Chronic (70) }\end{array}$ & $\begin{array}{c}-9.77 \\
-15.41\end{array}$ & $\begin{array}{l}{[-16.78 ;-2.76]} \\
{[-22.08 ;-8.75]}\end{array}$ & $<0.0001$ \\
\hline P. aeruginosa (mucoid strains) & $\begin{array}{l}\text { Transient (26) } \\
\text { Chronic (90) }\end{array}$ & $\begin{array}{l}-19.45 \\
-13.15\end{array}$ & $\begin{array}{c}{[-28.74 ;-10.16]} \\
{[-19.42 ;-6.89]}\end{array}$ & $<0.0001$ \\
\hline S. maltophilia & $\begin{array}{c}\text { Transient (22) } \\
\text { Chronic (8) }\end{array}$ & $\begin{array}{l}-14.19 \\
-10.26\end{array}$ & $\begin{array}{c}{[-24.22 ;-4.16]} \\
{[-26.44 ; 5.93]}\end{array}$ & 0.01 \\
\hline B. cepacia complex & $\begin{array}{l}\text { Transient (5) } \\
\text { Chronic (2) }\end{array}$ & $\begin{array}{c}18.60 \\
-13.15\end{array}$ & $\begin{array}{c}{[-2.02 ; 39.23]} \\
{[-44.69 ; 18.40]}\end{array}$ & 0.15 \\
\hline A. xylosoxidans & $\begin{array}{l}\text { Transient (3) } \\
\text { Chronic (13) }\end{array}$ & $\begin{array}{l}-6.32 \\
-17.97\end{array}$ & $\begin{array}{l}{[-32.99 ; 20.35]} \\
{[-31.32 ;-4.62]}\end{array}$ & 0,03 \\
\hline A. fumigatus & $\begin{array}{l}\text { Transient (57) } \\
\text { Chronic (57) }\end{array}$ & $\begin{array}{l}-2.99 \\
-1.53\end{array}$ & $\begin{array}{l}{[-10.05 ; 4.07]} \\
{[-8.65 ; 5.60]}\end{array}$ & 0.69 \\
\hline Scedosporium species & $\begin{array}{l}\text { Transient (0) } \\
\text { Chronic (10) }\end{array}$ & -7.42 & {$[-22.56 ; 7.52]$} & 0.22 \\
\hline C. albicans & $\begin{array}{l}\text { Transient (79) } \\
\text { Chronic (85) }\end{array}$ & $\begin{array}{l}-4.74 \\
-11.03\end{array}$ & {$\left[\begin{array}{l}{[-11.23 ; 1.74]} \\
{[-17.62 ;-4.44]}\end{array}\right.$} & 0.005 \\
\hline
\end{tabular}




\subsection{Bacterial and Fungal Colonisations Predicted ppFEV1 Level}

After the stepwise selection, colonisation with S. pneumoniae, non-pneumoniae Streptococcus species, A. xylosoxidans, S. maltophilia, mucoid and non-mucoid strains of $P$. aeruginosa, and $C$. albicans were included in the multivariable model (Table 4).

Table 4. Microbial factors at inclusion associated with the average change of ppFEV1 during the 2-year follow-up in the mixed linear model.

\begin{tabular}{|c|c|c|c|c|}
\hline Microorganisms & $\begin{array}{l}\text { Type of Colonisation } \\
\text { (Number of Patients) }\end{array}$ & $\begin{array}{c}\beta \\
\text { Coefficient }\end{array}$ & $95 \% \mathrm{CI}$ & $p$-Value \\
\hline S. pneumoniae & Transient (17) & 10.92 & $0.45 ; 21.40$ & 0.04 \\
\hline non-pneumoniae Streptococcus species & Transient (33) & -13.62 & $-25.12 ;-2.12$ & 0.02 \\
\hline A. xylosoxidans & $\begin{array}{l}\text { Transient (3) } \\
\text { Chronic (13) }\end{array}$ & $\begin{array}{c}-3.61 \\
-14.62\end{array}$ & $\begin{array}{l}-26.95 ;-2.30 \\
-32.08 ; 24.86\end{array}$ & 0.06 \\
\hline S. maltophilia & $\begin{array}{c}\text { Transient (22) } \\
\text { Chronic (8) }\end{array}$ & $\begin{array}{l}-11.93 \\
-11.02\end{array}$ & $\begin{array}{c}-21.38 ;-2.49 \\
-26.83 ; 4.79\end{array}$ & 0.02 \\
\hline P. aeruginosa (non-mucoid strains) & $\begin{array}{l}\text { Transient (53) } \\
\text { Chronic (70) }\end{array}$ & $\begin{array}{l}-7.54 \\
-9.63\end{array}$ & $\begin{array}{l}-14.30 ;-0.79 \\
-16.61 ;-2.65\end{array}$ & 0.01 \\
\hline P. aeruginosa (mucoid strains) & $\begin{array}{l}\text { Transient (26) } \\
\text { Chronic (90) }\end{array}$ & $\begin{array}{l}-18.26 \\
-10.41\end{array}$ & $\begin{array}{l}-27.20 ;-9.31 \\
-16.96 ;-3.87\end{array}$ & $<0.0001$ \\
\hline C. albicans & $\begin{array}{l}\text { Transient (79) } \\
\text { Chronic (85) }\end{array}$ & $\begin{array}{l}-5.12 \\
-10.26\end{array}$ & $\begin{array}{c}-11.17 ; 0.93 \\
-16.50 ;-4.02\end{array}$ & $<0.01$ \\
\hline
\end{tabular}

Transient as well as chronic colonisations with S. maltophilia, P. aeruginosa, and C. albicans were significantly and independently associated with ppFEV1 deterioration during the two years of follow-up. Furthermore, transient colonisation with non-pneumoniae Streptococcus was associated with a $13.6 \%$ decrease in ppFEV1 ( $\beta=-13.62,95 \% \mathrm{CI}$ : -25.12 ; $-2.12, p=0.02$ ). The effect of $A$. xylosoxidans and $S$. pneumoniae colonisation did not reach the significant threshold of 0.05 . The positive association between $S$. pneumoniae colonisation and the ppFEV1 level identified in the univariate analysis was confirmed in the multivariate model (Table 4).

A fungal colonisation was associated with a decrease of ppFEV1 $(\beta=-12.44,95 \% \mathrm{CI}$ : $-18.87 ;-6.02$ and $\beta=-6.33,95 \% \mathrm{CI}:-12.68 ; 0.01)$ for chronic and transient $C$. albicans colonisation, respectively).

Given the limited number of patients with chronic colonisation by B. cepacia species complex $(n=3)$, Mycobacterium avium complex $(n=4)$, Mycobacterium abscessus complex $(n=5)$, A. flavus $(n=9)$, C. glabrata $(n=3)$, and other Candida species including C. parapsilosis $(n=3)$, these microorganisms have not been taken into account in our mixed model. Results were adjusted based on medical centre, age, sex, BMI, presence of ABPA, and/or gastroesophageal reflux disease.

\subsection{Assessment of the Performance of our Mixed Model Using the Prognostic Score}

With the exception of $C$. albicans and non-pneumoniae Streptococcus spp. colonisations, transient and chronic colonisations with P. aeruginosa, A. xylosoxidans, and S. maltophilia were significantly associated with worse adjusted 3-years prognostic scores of death or LT [12] at inclusion (Table 5), confirming the suitable performance of our mixed model.

Results were adjusted based on medical centre, age, sex, BMI, presence of an ABPA, and/or a gastroesophageal reflux disease. 
Table 5. Microbial factors associated with the prognostic score for the prediction of within 3-years death or lung transplantation estimated at inclusion.

\begin{tabular}{|c|c|c|c|c|}
\hline Microorganisms & $\begin{array}{l}\text { Type of Colonisation } \\
\text { (Number of Patients) }\end{array}$ & $\begin{array}{c}\beta \\
\text { Coefficient }\end{array}$ & $95 \% \mathrm{CI}$ & $p$-Value \\
\hline S. pneumoniae & Transient (17) & -0.05 & $-0.81 ; 0.71$ & 0.90 \\
\hline non-pneumoniae Streptococcus spp. & Transient (33) & 0.53 & $-0.23 ; 1.30$ & 0.17 \\
\hline \multirow[t]{2}{*}{ A. xylosoxidans } & Transient (3) & 0.49 & $0.84 ; 2.59$ & \multirow[b]{2}{*}{0.001} \\
\hline & Chronic (13) & 1.72 & $-1.27 ; 2.25$ & \\
\hline \multirow[t]{2}{*}{ S. maltophilia } & Transient (22) & 0.90 & $0.21 ; 1.55$ & \multirow{2}{*}{0.01} \\
\hline & Chronic (8) & 0.88 & $-0.18 ; 1.99$ & \\
\hline \multirow[t]{2}{*}{ P. aeruginosa (non-mucoid strains) } & Transient (53) & 0.95 & $0.48 ; 1.43$ & \multirow[b]{2}{*}{$<0.0001$} \\
\hline & Chronic (70) & 1.30 & $0.80 ; 1.81$ & \\
\hline \multirow[t]{2}{*}{ P. aeruginosa (mucoid strains) } & Transient (26) & 0.91 & $0.26 ; 1.56$ & \multirow{2}{*}{0.01} \\
\hline & Chronic (90) & 0.41 & $-0.07 ; 0.88$ & \\
\hline \multirow[t]{2}{*}{ C. albicans } & Transient (79) & 0.21 & $-0.23 ; 0.65$ & \multirow{2}{*}{0.63} \\
\hline & Chronic (85) & 0.12 & $-0.32 ; 0.56$ & \\
\hline
\end{tabular}

\section{Discussion}

In the present work, we used microbial data from the most recent prospective multicentre cohort of French CF patients (MucoFong), based on a standardized sputum assessment protocol [19]. A linear mixed model was developed using a wide variety of microbial variables including fungi. It aimed to identify microbial species of ppFEV1 decline, with a statistical model that allowed patients to have varying baseline ppFEV1 measurements and different rates of change in ppFEV1 over time, as recently proposed [25].

Our results were in agreement with previous findings indicating that several concomitant chronic bacterial colonisations at the time of diagnosis (P. aeruginosa, B. cepacia, and S. maltophilia) confer a worse ppFEV1 level in CF. Traditional CF pathogens remain the best predictors of disease outcomes in adults with CF [3,5,6,10,12,14,16,17,26-33]. Transient bacterial colonisations, especially non-pneumoniae Streptococcus colonisation, were also factors associated with a worse level of ppFEV1 in our population. C. albicans colonisation was also associated with a worse level of ppFEV1. This last result is congruent with the principal component analysis in which C. albicans was more present in sputa from patients with severe CF disease [16]. It also supports results which evidenced that $C$. albicans colonisation presages FEV1 decline $[30,34]$, although the clinical relevance of yeast colonisation remains a matter of debate in $\mathrm{CF}$.

Transient colonisation with S. pneumoniae at inclusion appeared to be associated with a favourable ppFEV1 change, in agreement with a previous report showing that $S$. pneumoniae carriage is surprisingly high but not associated with more severe CF disease [35]. On the other hand, non-pneumoniae Streptococcus carriage was correlated with decreased ppFEV1 in one of the three models analysed in our population. Several studies reported the pathogenic potential of species such as Streptococcus anginosus or mitis group in CF [36,37]. Moreover, a longitudinal analysis of the bacterial composition and dynamics of sputum samples from a CF adult patient chronically colonised by P. aeruginosa revealed the key role of the Streptococcus milleri group in establishing chronic lung disease but also in exacerbation initiations [38]. These data highlight that the mechanisms of pathogenicity are complex and rely on the polymicrobial context of CF airways, in which P. aeruginosa is a recognized major pathogen interacting with the other members of the $\mathrm{CF}$ lung microbial community including non-pneumoniae Streptococcus, which may shape P. aeruginosa pathogenicity [38-41].

Several potential predictors, in particular colonisation with MSSA, MRSA, and A. fumigatus, were not shown to have a significant impact on the primary outcome (ppFEV1 average change during the 2 years of follow-up) in our model, in contrast to previous results $[28,29,31,32,42]$. However, MRSA prevalence appears to vary according to age and geographical situation in CF $[14,28,42]$. Regarding colonisation by moulds, the limited 
number of cases with Scedosporium species $(n=10)$ recorded in the present study may explain the lack of power to reach a significant threshold in the final analysis. Among our CF population, 80 patients $(26.8 \%)$ had A. fumigatus positive cultures at inclusion, including 57 with a chronic colonisation. In agreement with previous studies, we did not find a significant association between $A$. fumigatus colonisation and worse lung function $[12,17]$. However, Nkam et al. [12] showed that CF patients who died or underwent lung transplantation were more likely to have been diagnosed with ABPA, and there was a similar prevalence of ABPA between Nkam et al.'s population and ours $(18.9 \%$, Table 1 vs. $23.1 \%$ [12]). Both ABPA and Aspergillus sp. carriage have been associated with impaired lung function [30]. Conversely, the relationship between chronic colonisation with A. fumigatus and lung function recently evaluated using a linear mixed model appeared to exhibit a complex two-way relationship in CF [43].

Taken together, these results highlight (i) the potential pathogenicity in CF of species derived from the oral cavity and usually considered as clinically non-significant, and (ii) the polymicrobial signature of $\mathrm{CF}$ airway colonisation which may contribute as a collective entity to lung function decline $[36,44]$.

Our study has some limitations. The study targeted an adult population able to produce sputum samples (age median of 22.3 years; CI95\%: 16.7-29.9) leading to a selected population with more severe $\mathrm{CF}$ disease. The main outcome variable was ppFEV1, due to its major role in clinical practice and how it is currently the gold standard measure of disease severity. However, several recent parameters have emerged as promising alternative outcome variables to measure lung progression. Besides cross-sectional imaging by chest computed tomography or magnetic resonance imaging, the lung clearance index or multiple breath washout were shown to be more sensitive compared to ppFEV1, FVC, or to FEF25-75 [45-47]. Unfortunately, the study design did not allow us to identify nonpneumoniae Streptococci at the species level nor to quantify each microbial species since the MucoFong project was a multicentre study focused on identification and prevalence of fungi $[18,19]$. So far, the demographic, clinical, biological, and therapeutic characteristics of our population have been similar to published data [3,12]. In the last decade, linear and nonlinear models have emerged and demonstrated the clinical relevance in modelling pulmonary exacerbation or spirometry data in CF $[25,30,32,43,48]$.

These models identified several bacterial colonisations as factors associated with the ppFEV1 level, but few of them have addressed the mycobiota effect $[17,30,43]$. Two additional models scoring LT, mortality, and morbidity included the mycobiota [4,12]. Yet, estimating CF life expectancy, morbidity, mortality, and scoring the risk of LT or death are central but late outcomes, known to depend heavily on the CF patients' characteristics and their access to medical care and medications [44]. Additionally, prognostic factors have changed over time with the growing number of adults with $C F$, imposing a renewal in assessing lung function progression and microbial colonisation which may take advantage from next generation sequencing to simultaneously analyse the whole microbial community (bacteria, fungi, and viruses) without a priori knowledge of existing microorganisms [18,39].

To conclude, CF prognosis has dramatically improved over the past decades leading to an urgent need to reappraise the prognostic factors of CF progression, e.g., routinely assessing fungal colonisation and/or infection that have emerged as a new concern in CF $[1,30,34,43]$. Our model combining both items confirms the complex nature of CF lung disease, and provides new insights into bacterial and fungal colonisations as key factors in assessing and predicting lung function progression in CF. It emphasizes the need for regularly monitoring the bacterial and fungal colonisations of $\mathrm{CF}$ in lungs by using both culturing methods that allow microorganism phenotyping (such as in vitro sensitivity to antimicrobial agents) and molecular tools such as qPCR [49]. It also emphasizes the need, in the near future, for metataxonomics that provide the opportunity to identify all microbial species (including those difficult to culture) $[18,39,41]$.

Author Contributions: Conceptualization, L.D., R.T. and M.F.; methodology, F.F., R.E., L.D., R.T. and M.F.; software, F.F., R.E., P.S. and M.A.-F.; validation, L.D., R.T. and M.F.; formal analysis, F.F., R.E., 
P.S., F.L.-S., R.T. and L.D.; investigation, MucoFong Investigation Group, M.F. and S.B.; resources, L.D.; data curation, F.F. and R.E.; writing-original draft preparation, F.F., R.E., M.F., R.T. and L.D.; writing-review and editing F.F., R.E., P.S., F.L.-S., S.B., M.F., R.T., MucoFong Investigation Group and L.D.; visualization, L.D.; supervision, L.D.; project administration, L.D.; funding acquisition, L.D. All authors have read and agreed to the published version of the manuscript.

Funding: This project was supported by a research grant from "Vaincre La Mucoviscidose", VLM (MucoFong 2.0; RF20160501626/1/1/275), and L. Delhaes' team had annual grants from the University of Bordeaux and INSERM U1045.

Institutional Review Board Statement: The study was conducted according to the guidelines of the Declaration of Helsinki, and approved by the Institutional Ethics Committees of Lille University Hospital (CPP Number: 06/84, registered the 2 October 2006).

Informed Consent Statement: Informed consents were provided by all participants.

Data Availability Statement: The data that support the findings of this study are available from the corresponding author (L.D.), upon reasonable request.

Acknowledgments: The Mucofong Investigation Group: Jean-Philippe Bouchara and Marc Pihet (Angers University Hospital), Emilie Fréalle (Lille University Hospital), Yolande Lemeille (Grenoble University Hospital), Claudine Pinel (Grenoble University Hospital), Hervé Pelloux (Grenoble University Hospital), Gilles Gargala (Rouen University Hospital), Loic Favennec (Rouen University Hospital), Isabelle Accoceberry (Bordeaux University Hospital), Isabelle Durand-Joly (Dunkerque Hospital Center), Frédéric Dalle (Dijon University Hospital), Frédéric Huet (Dijon University Hospital), Annlyse Fanton (Dijon University Hospital), Amale Boldron (Dunkerque Hospital Center), Guy-André Loeuille (Dunkerque Hospital Center), Philippe Domblides (Bordeaux University Hospital), Bérengère Coltey (Marseille University Hospital), Isabelle Pin (Grenoble University Hospital), Catherine Llerena (Grenoble University Hospital), Françoise Troussier (Angers University Hospital), Christine Person (Angers University Hospital), Christophe Marguet (Rouen University Hospital), Nathalie Wizla (Lille University Hospital), Caroline Thumerelle (Lille University Hospital), Dominique Turck (Lille University Hospital), Anne Prévotat (Lille University Hospital), Benoit Wallaert (Lille University Hospital), Sylvie Leroy (Nice University Hospital).

Conflicts of Interest: The authors declare no conflict of interest.

\section{References}

1. Delhaes, L.; Touati, K.; Faure-Cognet, O.; Cornet, M.; Botterel, F.; DannaouiI, E.; Morio, F.; Le Pape, P.; Grenouillet, F.; Favennec, L.; et al. Prevalence, Geographic Risk Factor, and Development of a Standardized Protocol for Fungal Isolation in Cystic Fibrosis: Results from the International Prospective Study "MFIP". J. Cyst. Fibros 2019, 18, 212-220. [CrossRef] [PubMed]

2. Shwachman, H.; Kulczycki, L.L. Long-Term Study of One Hundred Five Patients with Cystic Fibrosis; Studies Made over a Fiveto Fourteen-Year Period. AMA J. Dis. Child 1958, 96, 6-15. [CrossRef]

3. Liou, T.G.; Adler, F.R.; FitzSimmons, S.C.; Cahill, B.C.; Hibbs, J.R.; Marshall, B.C. Predictive 5-Year Survivorship Model of Cystic Fibrosis. Am. J. Epidemiol. 2001, 153, 345-352. [CrossRef] [PubMed]

4. Flume, P.A.; Strange, C.; Ye, X.; Ebeling, M.; Hulsey, T.; Clark, L.L. Pneumothorax in Cystic Fibrosis. Chest 2005, 128, 720-728. [CrossRef] [PubMed]

5. Courtney, J.M.; Bradley, J.; Mccaughan, J.; O’Connor, T.M.; Shortt, C.; Bredin, C.P.; Bradbury, I.; Elborn, J.S. Predictors of Mortality in Adults with Cystic Fibrosis. Pediatr. Pulmonol. 2007, 42, 525-532. [CrossRef] [PubMed]

6. Buzzetti, R.; Alicandro, G.; Minicucci, L.; Notarnicola, S.; Furnari, M.L.; Giordano, G.; Lucidi, V.; Montemitro, E.; Raia, V.; Magazzù, G.; et al. Validation of a Predictive Survival Model in Italian Patients with Cystic Fibrosis. J. Cyst. Fibros. 2012, 11, 24-29. [CrossRef] [PubMed]

7. McCarthy, C.; Dimitrov, B.D.; Meurling, I.J.; Gunaratnam, C.; McElvaney, N.G. The CF-ABLE Score: A Novel Clinical Prediction Rule for Prognosis in Patients with Cystic Fibrosis. Chest 2013, 143, 1358-1364. [CrossRef] [PubMed]

8. Kerem, E.; Viviani, L.; Zolin, A.; MacNeill, S.; Hatziagorou, E.; Ellemunter, H.; Drevinek, P.; Gulmans, V.; Krivec, U.; Olesen, H.; et al. Factors Associated with FEV1 Decline in Cystic Fibrosis: Analysis of the ECFS Patient Registry. Eur. Respir. J. 2014, 43, 125-133. [CrossRef]

9. MacKenzie, T.; Gifford, A.H.; Sabadosa, K.A.; Quinton, H.B.; Knapp, E.A.; Goss, C.H.; Marshall, B.C. Longevity of Patients with Cystic Fibrosis in 2000 to 2010 and Beyond: Survival Analysis of the Cystic Fibrosis Foundation Patient Registry. Ann. Intern. Med. 2014, 161, 233-241. [CrossRef]

10. Aaron, S.D.; Stephenson, A.L.; Cameron, D.W.; Whitmore, G.A. A Statistical Model to Predict One-Year Risk of Death in Patients with Cystic Fibrosis. J. Clin. Epidemiol. 2015, 68, 1336-1345. [CrossRef] 
11. Szczesniak, R.; Heltshe, S.L.; Stanojevic, S.; Mayer-Hamblett, N. Use of FEV1 in Cystic Fibrosis Epidemiologic Studies and Clinical Trials: A Statistical Perspective for the Clinical Researcher. J. Cyst. Fibros. 2017, 16, 318-326. [CrossRef] [PubMed]

12. Nkam, L.; Lambert, J.; Latouche, A.; Bellis, G.; Burgel, P.R.; Hocine, M.N. A 3-Year Prognostic Score for Adults with Cystic Fibrosis. J. Cyst. Fibros. 2017, 16, 702-708. [CrossRef] [PubMed]

13. Keogh, R.H.; Szczesniak, R.; Taylor-Robinson, D.; Bilton, D. Up-to-Date and Projected Estimates of Survival for People with Cystic Fibrosis Using Baseline Characteristics: A Longitudinal Study Using UK Patient Registry Data. J. Cyst. Fibros. 2018, 17, 218-227. [CrossRef] [PubMed]

14. Marsteller, N.L.; Nussbaum, E.; Morphew, T.; Randhawa, I.S. Cystic Fibrosis Patients at Risk for Disease Progression Marked by Decline in FEV1\% Predicted: Development of the Cystic Fibrosis Risk of Disease Progression Score. J. Thorac. Dis. 2019, 11, 5557-5565. [CrossRef]

15. Liou, T.G.; Kartsonaki, C.; Keogh, R.H.; Adler, F.R. Evaluation of a Five-Year Predicted Survival Model for Cystic Fibrosis in Later Time Periods. Sci. Rep. 2020, 10. [CrossRef] [PubMed]

16. Paganin, P.; Fiscarelli, E.V.; Tuccio, V.; Chiancianesi, M.; Bacci, G.; Morelli, P.; Dolce, D.; Dalmastri, C.; De Alessandri, A.; Lucidi, V.; et al. Changes in Cystic Fibrosis Airway Microbial Community Associated with a Severe Decline in Lung Function. PLoS ONE 2015, 10, e0124348. [CrossRef] [PubMed]

17. Reece, E.; Segurado, R.; Jackson, A.; McClean, S.; Renwick, J.; Greally, P. Co-Colonisation with Aspergillus Fumigatus and Pseudomonas Aeruginosa Is Associated with Poorer Health in Cystic Fibrosis Patients: An Irish Registry Analysis. BMC Pulm. Med. 2017, 17. [CrossRef]

18. Soret, P.; Vandenborght, L.-E.; Francis, F.; Coron, N.; Enaud, R.; Avalos, M.; Schaeverbeke, T.; Berger, P.; Fayon, M.; Thiebaut, R.; et al. Respiratory Mycobiome and Suggestion of Inter-Kingdom Network during Acute Pulmonary Exacerbation in Cystic Fibrosis. Sci. Rep. 2020, 10. [CrossRef] [PubMed]

19. Coron, N.; Pihet, M.; Fréalle, E.; Lemeille, Y.; Pinel, C.; Pelloux, H.; Gargala, G.; Favennec, L.; Accoceberry, I.; Durand-Joly, I.; et al. Toward the Standardization of Mycological Examination of Sputum Samples in Cystic Fibrosis: Results from a French Multicenter Prospective Study. Mycopathologia 2018, 183, 101-117. [CrossRef]

20. Cantón, R.; Cobos, N.; de Gracia, J.; Baquero, F.; Honorato, J.; Gartner, S.; Alvarez, A.; Salcedo, A.; Oliver, A.; García-Quetglas, E. Antimicrobial Therapy for Pulmonary Pathogenic Colonisation and Infection by Pseudomonas Aeruginosa in Cystic Fibrosis Patients. Clin. Microbiol. Infect. 2005, 11, 690-703. [CrossRef]

21. Garcia-Clemente, M.; de la Rosa, D.; Máiz, L.; Girón, R.; Blanco, M.; Olveira, C.; Canton, R.; Martinez-García, M.A. Impact of Pseudomonas Aeruginosa Infection on Patients with Chronic Inflammatory Airway Diseases. J. Clin. Med. 2020, 9, 3800. [CrossRef] [PubMed]

22. To, K.; Cao, R.; Yegiazaryan, A.; Owens, J.; Venketaraman, V. General Overview of Nontuberculous Mycobacteria Opportunistic Pathogens: Mycobacterium Avium and Mycobacterium Abscessus. J. Clin. Med. 2020, 9, 2541. [CrossRef] [PubMed]

23. Amin, R.; Dupuis, A.; Aaron, S.D.; Ratjen, F. The Effect of Chronic Infection with Aspergillus Fumigatus on Lung Function and Hospitalization in Patients with Cystic Fibrosis. Chest 2010, 137, 171-176. [CrossRef] [PubMed]

24. Pellegrino, R.; Viegi, G.; Brusasco, V.; Crapo, R.O.; Burgos, F.; Casaburi, R.; Coates, A. Interpretative Strategies for Lung Function Tests. Eur. Respir. J. 2005, 26, 948-968. [CrossRef] [PubMed]

25. Albert, P.S.; Shih, J.H. An approach for jointly modeling multivariate longitudinal measurements and discrete time-to-event data. Ann. Appl. Stat. 2010, 4, 1517-1532. [CrossRef] [PubMed]

26. Emerson, J.; Rosenfeld, M.; McNamara, S.; Ramsey, B.; Gibson, R.L. Pseudomonas Aeruginosa and Other Predictors of Mortality and Morbidity in Young Children with Cystic Fibrosis. Pediatr. Pulmonol. 2002, 34, 91-100. [CrossRef]

27. VandenBranden, S.L.; McMullen, A.; Schechter, M.S.; Pasta, D.J.; Michaelis, R.L.; Konstan, M.W.; Wagener, J.S.; Morgan, W.J.; McColley, S.A. Lung Function Decline from Adolescence to Young Adulthood in Cystic Fibrosis. Pediatr. Pulmonol. 2012, 47, 135-143. [CrossRef] [PubMed]

28. Hubert, D.; Réglier-Poupet, H.; Sermet-Gaudelus, I.; Ferroni, A.; Le Bourgeois, M.; Burgel, P.-R.; Serreau, R.; Dusser, D.; Poyart, C.; Coste, J. Association between Staphylococcus Aureus Alone or Combined with Pseudomonas Aeruginosa and the Clinical Condition of Patients with Cystic Fibrosis. J. Cyst. Fibros. 2013, 12, 497-503. [CrossRef] [PubMed]

29. Dasenbrook, E.C.; Merlo, C.A.; Diener-West, M.; Lechtzin, N.; Boyle, M.P. Persistent Methicillin-Resistant Staphylococcus Aureus and Rate of FEV1 Decline in Cystic Fibrosis. Am. J. Respir. Crit. Care Med. 2008, 178, 814-821. [CrossRef] [PubMed]

30. Navarro, J.; Rainisio, M.; Harms, H.K.; Hodson, M.E.; Koch, C.; Mastella, G.; Strandvik, B.; McKenzie, S.G. Factors Associated with Poor Pulmonary Function: Cross-Sectional Analysis of Data from the ERCF. European Epidemiologic Registry of Cystic Fibrosis. Eur. Respir. J. 2001, 18, 298-305. [CrossRef]

31. Li, D.; Keogh, R.; Clancy, J.P.; Szczesniak, R.D. Flexible Semiparametric Joint Modeling: An Application to Estimate Individual Lung Function Decline and Risk of Pulmonary Exacerbations in Cystic Fibrosis. Emerg. Themes Epidemiol. 2017, 14, 13. [CrossRef] [PubMed]

32. Andrinopoulou, E.R.; Clancy, J.P.; Szczesniak, R.D. Multivariate Joint Modeling to Identify Markers of Growth and Lung Function Decline That Predict Cystic Fibrosis Pulmonary Exacerbation Onset. BMC Pulm. Med. 2020, 20, 142. [CrossRef] [PubMed]

33. Cogen, J.; Emerson, J.; Sanders, D.B.; Ren, C.; Schechter, M.S.; Gibson, R.L.; Morgan, W.; Rosenfeld, M. Risk Factors for Lung Function Decline in a Large Cohort of Young Cystic Fibrosis Patients. Pediatr. Pulmonol. 2015, 50, 763-770. [CrossRef] 
34. Chotirmall, S.H.; O’Donoghue, E.; Bennett, K.; Gunaratnam, C.; O’Neill, S.J.; McElvaney, N.G. Sputum Candida Albicans Presages $\mathrm{FEV}_{1}$ Decline and Hospital-Treated Exacerbations in Cystic Fibrosis. Chest 2010, 138, 1186-1195. [CrossRef] [PubMed]

35. Esposito, S.; Colombo, C.; Tosco, A.; Montemitro, E.; Volpi, S.; Ruggiero, L.; Lelii, M.; Bisogno, A.; Pelucchi, C.; Principi, N. Streptococcus Pneumoniae Oropharyngeal Colonization in Children and Adolescents with Cystic Fibrosis. J. Cyst. Fibros. 2016, 15, 366-371. [CrossRef] [PubMed]

36. Scott, J.E.; O'Toole, G.A. The Yin and Yang of Streptococcus Lung Infections in Cystic Fibrosis: A Model for Studying Polymicrobial Interactions. J. Bacteriol. 2019, 201, e00115-19. [CrossRef] [PubMed]

37. Hill, E.M. The Emergence of Streptococcus Anginosus Group as a Cystic Fibrosis Pathogen. Clin. Microbiol. Newsl. 2017, 39, 143-147. [CrossRef]

38. Sibley, C.D.; Parkins, M.D.; Rabin, H.R.; Duan, K.; Norgaard, J.C.; Surette, M.G. A polymicrobial perspective of pulmonary infections exposes an enigmatic pathogen in cystic fibrosis patients. Proc Natl. Acad. Sci. USA 2008, 105, 15070-15075. [CrossRef]

39. Zhao, J.; Schloss, P.D.; Kalikin, L.M.; Carmody, L.A.; Foster, B.K.; Petrosino, J.F.; Cavalcoli, J.D.; VanDevanter, D.R.; Murray, S.; Li, J.Z.; et al. Decade-long bacterial community dynamics in cystic fibrosis airways. Proc. Natl. Acad. Sci. USA 2012, 109, 5809-5814. [CrossRef]

40. O'Brien, S.; Fothergill, J.L. The role of multispecies social interactions in shaping Pseudomonas aeruginosa pathogenicity in the cystic fibrosis lung. FEMS Microbiol. Lett. 2017, 364, fnx128. [CrossRef] [PubMed]

41. Jorth, P.; Ehsan, Z.; Rezayat, A.; Caldwell, E.; Pope, C.; Brewington, J.J.; Goss, C.H.; Benscoter, D.; Clancy, J.P.; Singh, P.K. Direct Lung Sampling Indicates That Established Pathogens Dominate Early Infections in Children with Cystic Fibrosis. Cell Rep. 2019, 27, 1190-1204.e3. [CrossRef] [PubMed]

42. Jennings, M.T.; Riekert, K.A.; Boyle, M.P. Update on Key Emerging Challenges in Cystic Fibrosis. Med. Princ. Pract. 2014, 23, 393-402. [CrossRef]

43. Noni, M.; Katelari, A.; Dimopoulos, G.; Doudounakis, S.-E.; Tzoumaka-Bakoula, C.; Spoulou, V. Aspergillus Fumigatus Chronic Colonization and Lung Function Decline in Cystic Fibrosis May Have a Two-Way Relationship. Eur. J. Clin. Microbiol. Infect. Dis. 2015, 34, 2235-2241. [CrossRef] [PubMed]

44. Ratjen, F.; Bell, S.C.; Rowe, S.M.; Goss, C.H.; Quittner, A.L.; Bush, A. Cystic Fibrosis. Nat. Rev. Dis. Primers 2015, 1, 15010. [CrossRef] [PubMed]

45. Kent, L.; Reix, P.; Innes, J.A.; Zielen, S.; Le Bourgeois, M.; Braggion, C.; Lever, S.; Arets, H.G.; Brownlee, K.; Bradley, J.M.; et al. Lung clearance index: Evidence for use in clinical trials in cystic fibrosis. J. Cyst. Fibros. 2014, 13, 123-138. [CrossRef]

46. Stahl, M.; Wielpütz, M.O.; Graeber, S.Y.; Joachim, C.; Sommerburg, O.; Kauczor, H.U.; Puderbach, M.; Eichinger, M.; Mall, M.A. Comparison of Lung Clearance Index and Magnetic Resonance Imaging for Assessment of Lung Disease in Children with Cystic Fibrosis. Am. J. Respir. Crit. Care Med. 2017, 195, 349-359. [CrossRef] [PubMed]

47. Graeber, S.Y.; Boutin, S.; Wielpütz, M.O.; Joachim, C.; Frey, D.L.; Wege, S.; Sommerburg, O.; Kauczor, H.-U.; Stahl, M.; Dalpke, A.H.; et al. Effects of Lumacaftor-Ivacaftor on Lung Clearance Index, Magnetic Resonance Imaging, and Airway Microbiome in Phe508del Homozygous Patients with Cystic Fibrosis. Ann. Am. Thorac. Soc. 2021, 18, 971-980. [CrossRef] [PubMed]

48. Conrad, D.J.; Bailey, B.A.; Hardie, J.A.; Bakke, P.S.; Eagan, T.M.L.; Aarli, B.B. Median Regression Spline Modeling of Longitudinal FEV1 Measurements in Cystic Fibrosis (CF) and Chronic Obstructive Pulmonary Disease (COPD) Patients. PLoS ONE 2017, 12, e0190061. [CrossRef]

49. Boutin, S.; Weitnauer, M.; Hassel, S.; Graeber, S.Y.; Stahl, M.; Dittrich, A.S.; Mall, M.A.; Dalpke, A.H. One time quantitative PCR detection of Pseudomonas aeruginosa to discriminate intermittent from chronic infection in cystic fibrosis. J. Cyst. Fibros. 2018, 17, 348-355. [CrossRef] [PubMed] 